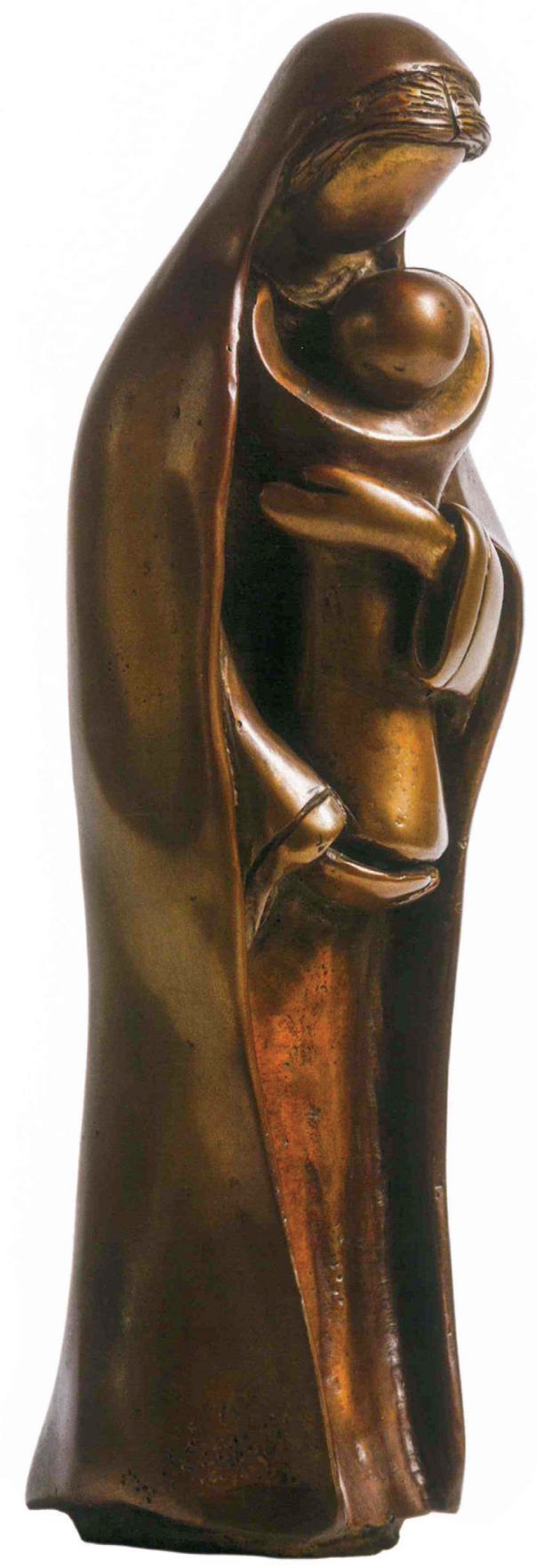





\section{VIDA Y OBRA DE LA RELIGIOSA QUE INMORTALIZÓ la Novena: la Madre María Ignacia}

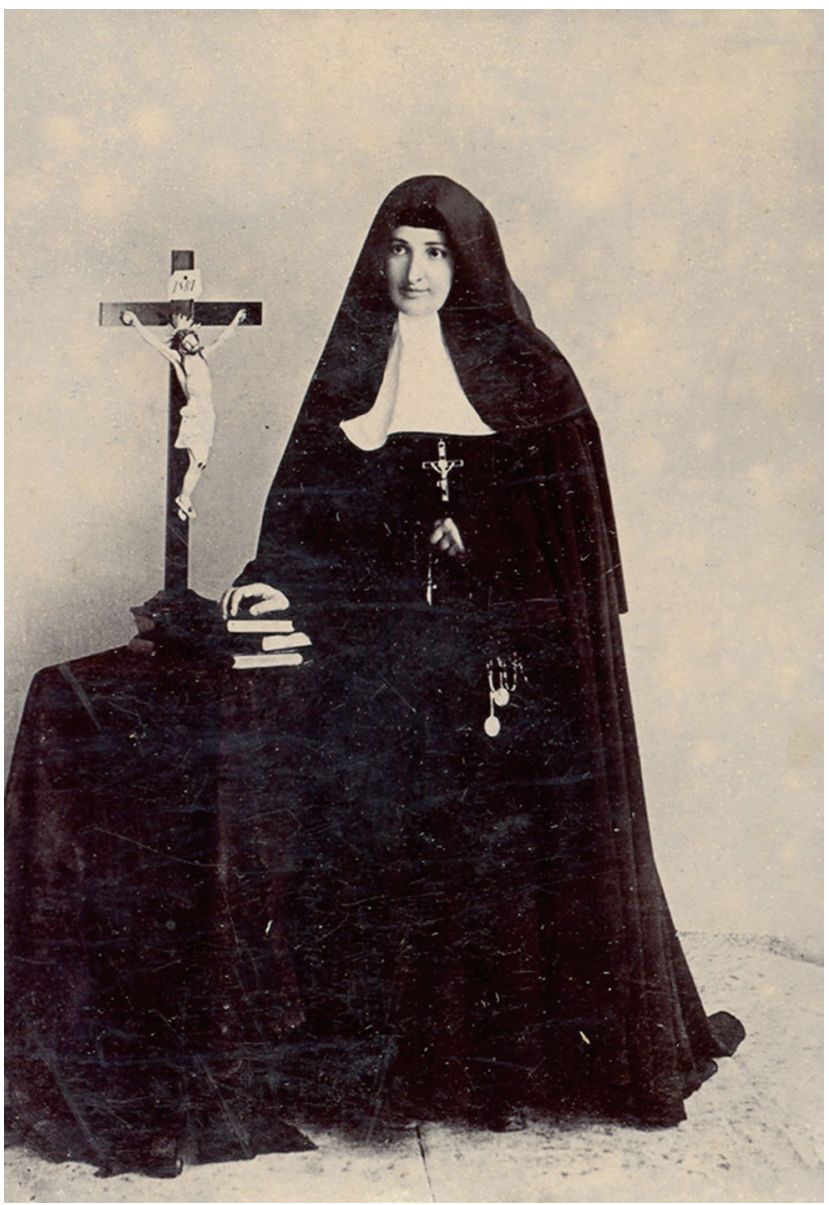

Figura 30. Madre María Ignacia.

Fuente: Biblioteca Luis Ángel Arango. 
La Novena para el Aguinaldo de Larrea no solo tuvo gran acogida en el territorio colombiano desde finales del siglo XVIII y todo el XIX, sino que se mantuvo incólume en todas sus ediciones y reimpresiones conocidas durante ese periodo. Por esa razón, una vez conocida su historia y difusión, es pertinente entender el contexto y los ideales de la madre María Ignacia, quien en un acto de profundo respeto a las tradiciones eclesiásticas y en especial por su amor y devoción al misterio de la encarnación, representado en la figura del Niño Dios, decidió transformar - y en palabras de algunos, actualizar y reinventar - la Novena como texto fundamental de la celebración navideña.

Para lograr este propósito, se intenta la reconstrucción biográfica de esta mujer, con el fin de conocer la importancia de las prácticas religiosas en la sociedad decimonónica y la vigencia o no de los ideales ascéticos presentes en la obra original del franciscano. Esto implica analizar no solo el proceso de transformación, es decir, determinar las continuidades, ampliaciones y cambios introducidos por la madre María Ignacia en el texto de la Novena para lograr una más fácil comprensión de su contenido y mayor cercanía con la población en general, sino el establecer el legado de la religiosa en función de la devoción al Niño Dios y la conmemoración de la Navidad incluso en La Enseñanza. Esto permitirá entender el paso de la costumbre de hacer la Novena a la consolidación de una tradición en relación con la práctica social de celebrar la Navidad por cuenta de la reinvención propuesta, que genera un nuevo lugar de enunciación para el texto renovado y lo configura como un patrimonio espiritual de los colombianos.

\section{De mujer ilustrada a religiosa de La Enseñanza: las vidas de Bertilda y María Ignacia}

La célebre madre María Ignacia, mencionada de forma recurrente en todos los comentarios y breves reseńas sobre la Novena que se han escrito, nació en Bogotá el 31 de julio de 1856 y tuvo por nombre Bertilda Samper Acosta, hija del matrimonio entre el notable humanista, literato y político José María Samper (1828-1889) y la prolífica escritora Soledad Acosta Kemble (18331913). Bertilda fue la mayor entre cuatro hermanas y la primera bendición de esta familia de alto estatus social y cultural, condición que le permitió ser una mujer muy ilustrada y diestra en múltiples campos, especialmente en la escritura. Sobre ella y su segunda hija, José María Samper relata a través del texto Historia del alma (1881) lo siguiente: 
Llevaba en sí misma la expresión de mis ideas, pues la había hecho dar el dulce nombre de Bertilda anagrama de Libertad, inventado por mí. La segunda, Carolina, llevaba el nombre de su adorada abuela materna, y había nacido en Guaduas el 15 de octubre de 1857. ¡Extrañas coincidencias! La primera había nacido bajo la advocación de San Ignacio de Loyola, de quien yo detestaba, y la segunda, bajo la de Santa Teresa de Jesús, de quien yo me burlaba, como Voltaire, por su "devota necedad" (Foz y Foz, 1997, p. 277).

Se sabe que durante su juventud viajó por varias partes del mundo y que fruto de aquellas experiencias aprendió inglés y francés y escribió algunos $L i$ bros de viajes, en los que reflejaba su formación académica y cultural.

Una de las coyunturas más importantes a lo largo de su vida fue la muerte de su padre, un hecho que haría a la familia Samper Acosta trasladarse a París, ciudad en donde Bertilda entraría en contacto con las comunidades de la Compañía de María de Burdeos y de Poitiers, que la llevarían a enaltecer y madurar su vocación. De acuerdo con Foz y Foz (1997), el acrecentamiento de dicho ideal religioso también se vería ampliamente nutrido en la experiencia que Bertilda adquirió en uno de sus viajes a Colombia, en donde "permaneció durante dos años pensionista en La Enseñanza", situación que "sería determinante en la orientación que daría a su vida después de cumplir cuarenta ańos" (p. 277). En este punto, cabe la pregunta sobre el porqué Bertilda esperaría a esa edad para hacer real su deseo de consagrarse a la vida religiosa.

$\mathrm{Al}$ respecto, es posible decir que fueron varios los obstáculos para que pudiese llegar a tal fin previamente, todos ellos concentrados principalmente en su familia, un punto comprensible si se tienen en cuenta los ideales políticos y religiosos en los que estaba envuelto su círculo familiar. En relación con sus padres, se tiene conocimiento de que don José María Samper se caracterizaba por ser un hombre creyente, pero enteramente anticlerical; su lógica liberal señalaba de nocivos e inútiles a frailes y religiosas por no significar ningún provecho social o económico para la nación y, por tanto, era inconcebible que le otorgase un permiso a su hija para entrar a un convento. Entre tanto, dońa Soledad Acosta de Samper, su madre, fue una mujer entregada a las letras y al fomento de la educación de las colombianas, por lo que a través de diferentes medios escritos transmitió sus ideas sobre el papel social de la mujer, opinó y criticó las extravagancias del feminismo y no estuvo ajena a contiendas ideológicas en la política nacional, una condición que imposibilitó una posición favorable para acceder al deseo de ingresar a la vida religiosa que manifestaba Bertilda. 
En cuanto a la figura de su abuela materna, de religión protestante y avanzada edad, ha de decirse que la estrecha relación entre ambas fue el mayor impedimento para tornar realidad su vocación. De acuerdo con lo documentado en el Libro primero de las difuntas de este Monasterio de la Madre de Dios y siempre Virgen Maria de la Enseñanza de Santafé, desde su fundación (Compañía de María Nuestra Señora, 1783-2003), el extremo amor que sentía doña Bertilda por su abuela le impidió abandonarla un solo momento "hasta lograr de Dios la abjuración de sus errores y verla morir en el seno de la Santa Iglesia Católica", por lo que se quedaría siempre con ella aun cuando aquel acto le implicase "continuos sacrificios y desvelos para lograrlo". En últimas, fue después de la muerte de su abuela cuando "entró como postulante el día del Nuestra Señora del Pilar, y tomó el santo hábito el 13 de Noviembre fiesta de San Estanislao" (Compañía de María Nuestra Señora, 1783-2003, f. 135), tal como consta en el Libro toma de hábito y profesión (Compañía de María Nuestra Señora, s. f. b) del Colegio La Enseñanza:

\section{Hermana Bertilda Samper.}

Hija legitima del Señor D. José María Samper y de la Sra. Soledad Acosta, de familia muy conocida en Bogotá por ser nobleza e ilustración. Tomó el hábito para religiosa de coro, después de un mes de postulado, y a los 40 años de edad del día 13 de noviembre de 1896, en la Misa que celebró el Ilmo. Señor Dr. Bernardo Herrera R. Arzobispo de Bogotá. Con permiso del Prelado, cambió su nombre en el de María Ignacia por haber nacido el día del Sto. fundador de la compañía de Jesús. Y para que en todo tiempo conste firmamos.

María IgnaCia SAMPER

Mercedes Caro, Priora

(Compañía de María Nuestra Señora, s. f. b, f. 180)

Sobre el tema, es importante mencionar que, al ingresar a la vida religiosa, Bertilda decidió usar sus dos primeros nombres, un asunto que ella misma expone al escribirle a una amiga francesa las siguientes letras:

Yo nací el 31 de Julio y recibí el nombre de María Ignacia Bertilda. Mi padre, que tenía entonces ideas muy liberales, inventó el tercer nombre para mi por ser el anagrama de Libertad (Liberté). Tu sabes bien que no existen nombres más bellos y que yo prefiera 
más que los dos primeros, bien significativos para una Hija de Nuestra Señora y de San Ignacio. Además, antes de entrar en el convento, prometí al gran santo retomar su nombre si él allanaba los obstáculos que se oponían a la realización de mis deseos. El santo no falló en darme respuesta; tampoco yo puedo fallarle a él (Foz y Foz, 1997, p. 277).

Tenía ya cuarenta años y unos meses cuando la madre María Ignacia entró en el noviciado, y aunque hacía ya algún tiempo que había solicitado su admisión en la comunidad, fue a raíz de los motivos ya expuestos que no le había sido posible concretar tal petición. Retomando lo descrito en el Libro primero de las difuntas de este Monasterio de la Madre de Dios y siempre Virgen María de la Enseñanza de Santafé, Desde su fundación, se dice que:

Como había sido colegiala dos ańos en nuestro internado, no le costó trabajo el conocer y tratar a las Religiosas, como sucede a otras, siendo ya de edad avanzada, desde luego puso todo su estudio en ejercitarse en las virtudes de la humildad y mortificación, sobre todo después de pronunciados sus votos solemnes; como la pobreza es tan hermana de la mortificación la ejercitó con empeño, buscando y pidiendo para sí, los muebles y cuanto servía para su uso lo más más pobre y viejo que pudiese conseguir, en la comida hasta buscar cosas repugnantes, y cuando servía en el reformatorio quedándose con los sobrados de otros platos y dejando lo limpio y aseado que le servían, cosa más de admirar en ella siendo de familia acomodada y de mucho trato social, tanto en lo dicho como en conseguir permiso para practicar mortificaciones corporales o penitencias se valía de palabras tan edificantes $Y$ persuasivas que salía con su pretensión, lo mismo procuraba con la humildad, ya acusándose de cosas que no eran propiamente faltas pero que ella quería que se viesen como tales, o ya achacándoselas a sí siendo de otras. En fin quería (como decía ella), redimir el tiempo perdido, pues que habiendo llegado tarde a la Religión, apresurar el paso para no quedar atrás de las que entraron en sus primeros ańos (Compañía de María Nuestra Señora, 1783-2003, ff. 135-136).

Para el 24 de septiembre de 1898, la madre María Ignacia emitió la profesión de sus votos nuevamente en presencia del arzobispo de Bogotá, Bernardo 
Herrera Restrepo, tal como consta en el Libro en que se hayan los requerimientos y profesiones de las religiosas del Monasterio de Nuestra Señora de Enseñanza:

La cual cumplidos dos ańos de noviciado, y previos todos los requisitos necesarios, obligándose bajo juramento a mantener la vida común y a no admitir jamás criadas; profeso solemnemente el día 24 de noviembre de 1898, en la Misa, que según el Ceremonial de la Orden celebró el Ilmo. Señor Dr. Bernardo Herrera R. Arzobispo de Bogotá; siendo Priora la R. Madre Mercedes Caro. Y para que conste en todo tiempo firmamos.

María IgnaCia SAMPer (Compañía de María Nuestra Señora, s.f. b, f. 180)

Asimismo, el Arzobispo de Bogotá hizo comparecer a la novicia Bertilda Samper Acosta según se demuestra en aquel mismo libro casi un mes después:

En Bogotá a veintiuno de noviembre de mil ochocientos noventa e ocho, en la casa de Religiosas de la Enseñanza, el Ilmo. y Rmo. Sr. Arzobispo Dr. D. Bernardo Herrera Restrepo hizo comparecer a la novicia Bertilda Samper Acosta, quien previo el juramento del caso dijo:

1. Que se llama en Religión e María Ignacia.

2. Que es hija legitima del sr. José María Samper y de la Sra. Soledad Acosta; natural de Bogotá; de cuarenta y dos años de edad; y que hace dos años que tomó el hábito.

3. Que es católica, apostólica, romana

4. Que no tiene deudas en el mundo

5. Que no tiene dada palabra de matrimonio, ni nada que le impida profesar

6. Que no tiene enfermedad que le impida vivir en comunidad.

7. Que su entrada es libre y espontánea.

8. Que se compromete a no pedir criada para sí ni para la comunidad

9. Que se compromete a trabajar por la observancia de las Reglas y constituciones. 
10. Que no necesita más tiempo para deliberar.

11. Que conoce las reglas que va a profesar.

Leída la ratifica y firma Bernardo arzobispo de Bogotá

(Compañía de María Nuestra Señora, s. f. a, ff. 45-46).

\section{Los escritos de la madre María Ignacia: el piadoso fervor por el Nińo Jesús y la Navidad}

La madre María Ignacia poseía no solo un alto grado de educación, sino un talento superior para la escritura, especialmente para la poesía. De acuerdo con Foz y Foz (1997), esta era una destreza que perfeccionó durante su estadía en Europa, específicamente en Francia, pues fue durante sus últimos años allí que compuso textos que, aunque de diversa índole, fueron predominantemente de carácter religioso. Todas las composiciones que de ella se conocen generalmente "respiran un perfume sagrado y un amor divino que levantan el corazón y la mente a Dios. Su devoción especial fue al Santísimo Sacramento del altar y a la santa Infancia" (Compañía de María Nuestra Señora, 1783-2003, f. 136), de modo que la totalidad de sus poesías tienen un tema predilecto referido al amor por el Nińo Jesús. Precisamente, fue este don para escribir lo que la hizo protagonista no solo en la composición de diálogos, comedias y obras de teatro requeridas para la formación de las niñas en el Colegio de La Enseñanza, sino en la instrucción y fomento de clases de idiomas para las internas.

Son varios los escritos de la madre María Ignacia que podrían ejemplificar estos temas, tal es el caso del texto titulado La Nochebuena de la tía Verruga (Samper, 1892, ff. 44-56), una obra de teatro escrita para el colegio, que demanda la actuación de nińas entre 7 y 10 ańos de edad. Su contenido consta de doce páginas, se divide en siete escenas y contempla siete personajes. Realmente es una bella obra que permite conocer más sobre la devoción que se profesaba al Divino Nińo y sirve como una muestra de la celebración cotidiana de la Navidad en relación con la gastronomía y el lenguaje de las personas del común: 
Escena I (p. 45)

[...] Canturréa [La tía

verruga]:
Esta noche es Nochebuena

Y bajan los angelitos

A repartir mojicones

Y buńuelos exquisitos.

$[\ldots]$

Escena II (p. 46)

Tía Cuchufa, preguntándole a la Tía Verruga: "Y ¿por qué está buste’ tan solita y tan ocupada en este día de Nochebuena, cuando todas las tiendas están llenas de cosas buenas, y todo el mundo anda por la ciud' mirándolas, y comprando pasteles y dulces pa' cenar esta noche"

Tía Verruga: "El probe no puede dejar su oficio, porque si lo hace no come" Tía Cachufa: "yo soy probe también, y puede dejar el mio pa' ir a comprar estos buñuelitos. Una vez en el año hay que hacer alguna calaverada

$[\ldots]$

Escena VI (p. 53)

Al ver el contenido de la bolsa las niñas exclaman:

$$
\begin{aligned}
& \text { "1a }- \text { Ay cuántos bizcochos y galletas } \\
& 2^{\mathrm{a}}-\mathrm{Y} \text { miren! También hay pasas y } \\
& \text { almendras. } \\
& 3^{\mathrm{a}}-\mathrm{Y} \text { unos roscones como yo quería } \\
& 4^{\mathrm{a}}-\mathrm{Y} \text { unos corderitos de alfeñique. } \\
& \text { Sentémonos a comer } \\
& 1^{\mathrm{a}}-\mathrm{Y} \text { si viene mamá señora ¿qué dirá? } \\
& 3^{\mathrm{a}}-\text { Pus, ella misma seria la que nos } \\
& \text { preparó la sorpresa }
\end{aligned}
$$

\section{$[\ldots]$}

\section{Escena VII (p. 55)}

Tía Verruga: "Orita me voy pa la calle a comprar unos buñuelos y unas empanadas como para la mesa del Rey, eso sí! Pero mientras tanto, echemos una mano de baile y de canto pa celebrar al divino Niño".

Otro de los tantos ejemplos que pueden resaltarse, es la creación de una segunda obra de teatro muy corta, tan solo de cuatro páginas, a partir de la transcripción de un texto publicado en la Revista Popular de Barcelona titulado "Los arrullos de la Virgen" (Samper, 1892, ff. 36-39). Su representación recrea una gran escena alusiva al nacimiento del Nińo Jesús, pero resulta interesante el estribillo que reza: “A la nanita, nana, nanita ea!", una frase que trascendería el espacio del Colegio La Enseñanza para consolidarse como uno de los villancicos más populares en Colombia durante los siglos XX y XXI. 


\begin{tabular}{|c|c|}
\hline $1^{\circ}$ Ángel - & Señora, bosteza el Nińo y no nos quiere mirar! \\
\hline $2^{\circ}$ Ángel - & Tenía sueño!... con cariño entonémosle un cantar \\
\hline Juntos: & $\begin{array}{l}\text { (cantando y meciendo pausadamente la cuna) } \\
\text { ¡A la nanita, nana, } \\
\text { Nanita ea! } \\
\text { El Niño tiene sueño: } \\
\text { ¡Bendito sea! }\end{array}$ \\
\hline Virgen - & $\begin{array}{l}\text { Pimpollo de azucena, lirio en capullo; } \\
\text { Duérmete sin recelo mientras te arrullo; } \\
\text { Duérmete, que del alma mi canto brota, } \\
\text { Y un deliquio de amores es cada nota. } \\
\text { ¡Oh Niño en cuyos ojos el sol fulgura! } \\
\text { Cerrarlos es cercarme de noche oscura; } \\
\text { Pero cierra bien mis, los ojos bellos. } \\
\text { Aunque tu Madre muera sin verse en ellos. } \\
\text { Fuentecilla que corre clara y sonora, } \\
\text { Ruiseńor que en la selva cantando llora, } \\
\text { Callad mientras la cuna se balancea: } \\
\text { A la nanita, nana, nanita ea! }\end{array}$ \\
\hline $1^{\circ}$ Ángel - & $\begin{array}{l}\text { Calla, calla!... Tranquilo se ve su sueño... } \\
\text { Otro arrullo cantemos al dulce Dueño! }\end{array}$ \\
\hline $2^{\circ}$ Ángel - & $\begin{array}{l}\text { El Niño los deditos frunció, Señora! } \\
\text { ¿Qué será lo que quiere decir ahora? }\end{array}$ \\
\hline $\begin{array}{l}\text { Juntos (como } \\
\text { antes) }\end{array}$ & $\begin{array}{l}\text { A la nanita, nana } \\
\text { Nanita ea } \\
\text { El Niño tiene sueño: } \\
\text { ¡Bendito sea! }\end{array}$ \\
\hline Virgen - & $\begin{array}{l}\text { Ay! Que manos tan bellas las de mi Niño! } \\
\text { ¡Suavidad y blancura tienen de armiño! } \\
\text { ¡Qué dolor tan de muerte para esta noche } \\
\text { Cuando fiero verdugo se las talache! } \\
\text { Sienes de leche y rosa, sienes divinas } \\
\text { Que habéis de ser punzadas por las espinas } \\
\text { Dejadme, blancas sienes, que os bese ahora } \\
\text { Con la piedad del ángel que a Dios adora. }\end{array}$ \\
\hline
\end{tabular}


Y tú, triste presagio que me torturas

Almáciga de penas y de amarguras;

Huye, mientras la cuna se balancea;

A la nanita, nana, nanita ea!

$1^{\circ}$ Ángel -

Este Nińo cales que yo vigilo

Los labios y los brazos mueve intranquilo!

$2^{\circ}$ Ángel -

Ay, que no se despierte, ni con pesares!

Entonémosle pronto nuestros cantares!

Juntos (como

A la nanita, nana

antes)

Nanita, ea!

El Niño tiene sueño,

¡Bendito sea!

Virgen - $\quad$ Boquita de amapolas y de claveles,

Que has de ser impregnada de amargas hieles;

[No visible]

Por Dios, Hijito mío, no abras los brazos;

Que, al abrirlos, el alma me haces pedazos;

Pues me imagino verte cadáver y esto,

Colgante, desangrando y el pecho abierto

¡Pero huid, negras sombras de mis dolores,

No me nubleis el cielo de mis amores!

Huid, mientras la una se balancea;

¡A la nanita, nana, nanita, ea!

$1^{\circ}$ Ángel - $\quad$ En los labios del niño luce indecisa

No sé qué misteriosa, dulce sonrisa.

$2^{\circ}$ Ángel - $\quad Y$ parece que dice como una frase...

Cantémosle de nuevo, pues que le place.

Juntos (como A la nanita,

antes) nana, nanita ea!

El Niño tiene sueño...

¡Bendito sea!

Virgen - $\quad$ Manojito de rosas y de alelíes;

¿Qué es lo que estas soñando que te sonríes?

¿Cuáles son tus ensueños?... dilo, alma mia! 
Mas... ¿qué es lo que murmuras? ... ¿Eucarístia?

Yo no sé lo que es eso, Niño del alma;

Mas, pues que tu sonrisa mi pena calma,

Sigue, sigue sońando, mi dulce Dueño,

Sin que te ahuyente tan grato ensueño.

Pajarillos y fuentes, auras y brisas,

Respetad esos sueños y estas sonrisas...

Callad mientras la cuna se balancea;

A la nanita nana, nanita ea.

$1^{\circ}$ Ángel - $\quad$ ¡Oh Niño! De los cielos dicha y fortuna

Dejad que os contemplemos aquí en la cuna!

$2^{\circ}$ Ángel - $\quad$ Dejar que estos querubes que os aman tanto

Juntos Os arrullen gozosos con suave canto

A la nanita, nana,

Nanita, ea!

¡El Niño está dormido!

Bendito sea!

(Transcrito en Samper, 1892, ff. 36-39).

Estos dos ejemplos demuestran no solo del talento de la madre María Ignacia para escribir textos sencillos y armónicos, sino que también son el reflejo de su condición ilustre y de su relación con las dinámicas culturales del exterior. El ejercicio de lectura, transcripción, divulgación y, por supuesto, de enseńanza, se constituye verdaderamente en un complejo de prácticas que emanan de los constructos comportamentales dispuestos en la esfera de lo público, que solo podía tener una dama con mucha experiencia y bagaje cultural, quien una vez dentro de una comunidad religiosa personificaría el ideal de la mujer cristiana fiel y celosa de los mandatos y preceptos divinos. De ahí que su vida estuviera dedicada a enaltecer con insistencia los valores religiosos dentro de la estructura educativa promulgada por aquel entonces, por lo que virtudes como la generosidad y la abnegación de esta mujer fueron condiciones más que necesarias para la edificación moral y social que decidió emprender, sobre todo ante los ojos de una sociedad que apremiaba pulcritud y en la que la figura femenina debía caracterizarse por ser la contenedora de 
las buenas costumbres. Aquellas ideas son también expuestas por su madre, Soledad Acosta de Samper:

La mujer será un órgano dedicado al bello sexo y al bien y servicio de el bajo todos los aspectos. No solo procuraremos agradar, sino que nos esforzaremos principalmente por consolarla en sus penas y amarguras, alentarla en el cumplimiento de sus obligaciones [...] en medio de arduos deberes íntimos y ocupaciones domesticas, que hay en el fondo de la existencia de las mujeres de nuestra patria. Otras plumas habrá que se dedicaran a halagar la vanidad de la mujer, a elogiar su belleza y el encanto de sus gracias, encomiando su donaire y gentileza; nosotras procuramos hablar de su corazón y a su conciencia, recordándola a cada paso que no ha nacido solamente para ser feliz sobre la tierra, sino para realizar muy altos fines de la providencia (Acosta, 1879, p. 1).

Pero la madre María Ignacia también se involucró en otro tipo de producción textual, de manera que tuvo una actividad literaria continua entre 1899 y 1910. Se trató de escritos de carácter histórico asociados a la Orden de la Compañía de María Nuestra Señora, temas relacionados con la fundación de la Casa de Medellín (1899), la beatificación de Juana de Lestonnac (19001901), las fiestas y celebraciones escolares (1900-1911), otras de carácter biográfico como "La juventud de Juana de Lestonnac" y "María Clemencia Caicedo y el origen de La Enseńanza en Bogotá", sin dejar de lado algunas alegóricas como "Los meses del año", "Las estaciones del año: las edades de la vida", "La ciencia, el arte y la Fe" y "Las hijas de América Latina”, en las que se hallan reflexiones sobre los tiempos de la vida enmarcados en contenidos claramente religiosos y exaltaciones al continente americano. No obstante, pese a su rica obra literaria su reconocimiento principal estará dado por aquellos escritos relacionados con temas de Adviento y Navidad:

Las "Meditaciones de Adviento" escritas en cuidada prosa y con anotaciones de la Escritura, y el poema "Natum regem angelorum" reflejan la devoción que sintió por la infancia de Jesús, que profundizó en la espiritualidad de la carmelita Margarita de Beaune. Los sentimientos de ternura y su fácil versificación le inspiran unos gozos, en metro corto y asonante, que recuerdan los villancicos del Siglo de Oro español. Esta devoción que cultivó durante toda 
su vida, permite otorgarle una función relevante en la adaptación y divulgación de la popular Novena de Aguinaldo, que ella misma refrenda en testimonio autógrafo (Foz y Foz, 1997, p. 279).

\section{La adaptación de la Novena para el Aguinaldo de Larrea: una reinvención afortunada}

Se ha mencionado que debido al contacto del padre Larrea con dońa María Clemencia, y la relación de esta última con el Colegio de La Enseñanza, fue muy posible que la obra piadosa fuera conocida en Bogotá, particularmente entre las hermanas de la Compañía y sus estudiantes, entre ellas Bertilda Samper Acosta, quién luego sería la artífice de una de las más profundas y populares modificaciones del texto, versión que sería conocida y pasaría a la historia como Novena del Niño Dios: arreglada y aumentada por la madre María Ignacia, todo un fenómeno que permanece hasta nuestros días en el patrimonio espiritual de los colombianos (Nieto, 2011, p. 10).

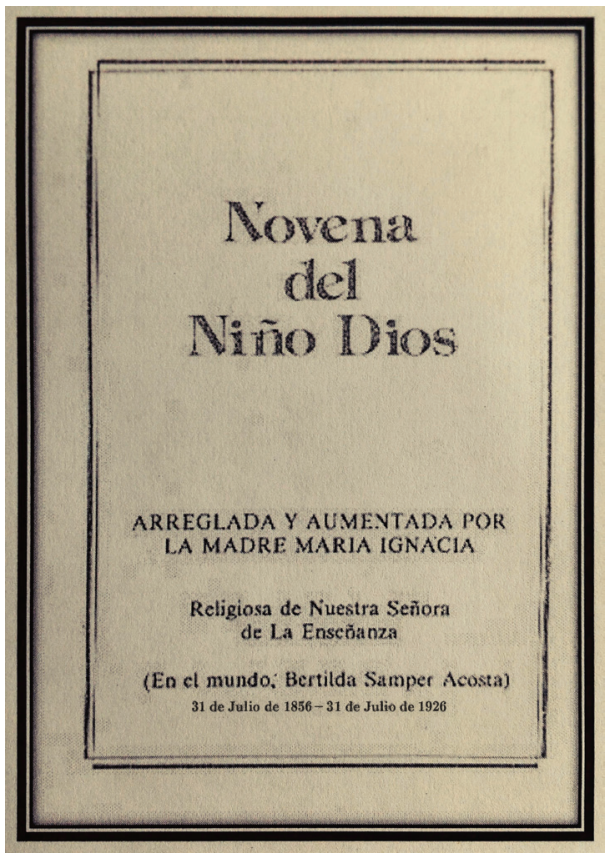

Figura 31. Portada de la Novena del Niño Dios. Arreglada y aumentada por la madre María Ignacia (1910).

Fuente: Biblioteca Luis Ángel Arango, Sala de Libros Raros y Manuscritos. 
En relación con la adaptación que hizo la madre María Ignacia, Arboleda (2011) plantea que en parte se trata de la inclusión de una traducción al español de seis de las siete antífonas mayores que se cantaban en latín desde el 17 hasta el 23 de diciembre en el Oficio de las Vísperas, de las cuales el padre Larrea solo había considerado tres en su Novena para el Aguinaldo. Por eso es posible contrastarlas.

Tabla 1. Comparación entre los textos de las antifonas mayores, la versión de Larrea y la de la madre María Ignacia

\begin{tabular}{|c|c|c|}
\hline ANTÍFONAS MAYORES & $\begin{array}{l}\text { VERSIÓN DEL PADRE } \\
\text { LARREA (1803) }\end{array}$ & $\begin{array}{l}\text { VERSIÓN DE LA MADRE } \\
\text { MARÍA IGNACIA (1910) }\end{array}$ \\
\hline $\begin{array}{l}\text { O Sapientia } \\
\text { quae ex ore Altissimi } \\
\text { prodisti attingens a fine } \\
\text { usque ad finem fortiter, } \\
\text { suaviter disponensque } \\
\text { ommnia } \\
\text { veni ad docendum nos } \\
\text { viam prudentiae. }\end{array}$ & & $\begin{array}{l}\text { Oh sapiencia del Dios } \\
\text { soberano que a infantil } \\
\text { alcance te rebajas sacro. } \\
\text { Oh divino Nińo ven para } \\
\text { enseñarnos la prudencia } \\
\text { que hace verdaderos sabios. }\end{array}$ \\
\hline $\begin{array}{l}\text { O Adonai et Dux domus } \\
\text { Israel } \\
\text { qui Moysi in igne flammae } \\
\text { rubi apparuisti } \\
\text { et ei in Sina legem dedisti } \\
\text { veni ad redimendum } \\
\text { nos in brachio extento. }\end{array}$ & & $\begin{array}{l}\text { Oh, Adonaí potente que } \\
\text { a Moiséis hablando de } \\
\text { Israel al pueblo disteis los } \\
\text { mandatos. } \\
\text { ¡Ah! Ven prontamente para } \\
\text { rescatarnos y que un niño } \\
\text { débil muestre fuerte brazo. }\end{array}$ \\
\hline $\begin{array}{l}\text { O Radix Jesse } \\
\text { qui stas in signum } \\
\text { populorum } \\
\text { super quem continebunt } \\
\text { reges os suum } \\
\text { quem gentes deprecabuntur } \\
\text { veni ad liberandum nos } \\
\text { jam noli tardare. }\end{array}$ & $\begin{array}{l}\text { Raíz de Jesé Adonaí } \\
\text { Sagrado Sapiencia del } \\
\text { Padre y de su luz Rayo. }\end{array}$ & $\begin{array}{l}\text { Oh, raíz sagrada de José, } \\
\text { que en lo alto presentas al } \\
\text { orbe tu fragante nardo. }\end{array}$ \\
\hline
\end{tabular}




\begin{tabular}{|c|c|c|}
\hline ANTÍFONAS MAYORES & $\begin{array}{l}\text { VERSIÓN DEL PADRE } \\
\text { LARREA (1803) }\end{array}$ & $\begin{array}{l}\text { VERSIÓN DE LA MADRE } \\
\text { MARÍa IGNACIA (1910) }\end{array}$ \\
\hline $\begin{array}{l}\text { O clavis David } \\
\text { et sceptrum domus Israel } \\
\text { qui aperis et nemo claudit } \\
\text { claudis et nemo aperit veni } \\
\text { et educ vinctum de domo } \\
\text { carceris } \\
\text { seentem in tenebris e } \\
\text { umbra mosrtis }\end{array}$ & $\begin{array}{l}\text { Llave de David } \\
\text { Legislador Sabio } \\
\text { Guía de tu pueblo y Rey } \\
\text { soberano. }\end{array}$ & $\begin{array}{l}\text { Llave de David } \\
\text { que abre al Desterrado } \\
\text { las cerradas puertas } \\
\text { del regio palacio. } \\
\text { Sácanos, oh, Nińo, } \\
\text { con tu blanda mano } \\
\text { de la cárcel triste } \\
\text { que labró el pecado. }\end{array}$ \\
\hline $\begin{array}{l}\text { O Oriens } \\
\text { splendor lucis aeternae } \\
\text { et sol justitiae } \\
\text { veni et illumina in tenebris } \\
\text { et umbra mortis }\end{array}$ & & $\begin{array}{l}\text { Oh lumbre de } \\
\text { Oriente, } \\
\text { sol de eternos rayos } \\
\text { que entre las } \\
\text { tinieblas } \\
\text { tu esplendor } \\
\text { veamos. }\end{array}$ \\
\hline $\begin{array}{l}\text { O Rex gentium } \\
\text { et desideratus earum } \\
\text { lapisque angularis, qui facis } \\
\text { utraque unum } \\
\text { veni et salva hominem } \\
\text { quem de limo formasti }\end{array}$ & & $\begin{array}{l}\text { Rey de las naciones } \\
\text { Emanuel preclaro, } \\
\text { de Israel anhelo } \\
\text { Pastor del Rebaño. }\end{array}$ \\
\hline $\begin{array}{l}\text { O Emmanuel } \\
\text { rex et legifer noster } \\
\text { exspectatio gentium et } \\
\text { salvator } \\
\text { earum } \\
\text { veni ad salvandum nos } \\
\text { Domine } \\
\text { Deus Noster. }\end{array}$ & $\begin{array}{l}\text { O Manuel divino mi } \\
\text { amante y mi amado } \\
\text { Ven al mundo yá } \\
\text { apresura el Paso. }\end{array}$ & \\
\hline
\end{tabular}

Es preciso resaltar que en la adaptación de la religiosa bogotana se presenta, en paralelo, la modificación de algunos gozos en la sección denominada "Aspiraciones". Al respecto es posible advertir que, si bien algunas novenas 
del periodo hispánico contaban con gozos, el aporte de la madre María Ignacia frente a la Novena del padre Larrea fue su vocabulario más sencillo y de fácil recordación, pero no porque este haya utilizado un lenguaje complejo o difícil, sino porque la lengua durante más de un siglo sufrió algunas modificaciones y desde luego evolucionó, de manera que se trataba más bien de un lenguaje anticuado u obsoleto para la época. En la tabla 2 se exponen los cambios de manera puntual.

\section{Tabla 2. Comparación entre los textos del padre Larrea y la madre María Ignacia.}

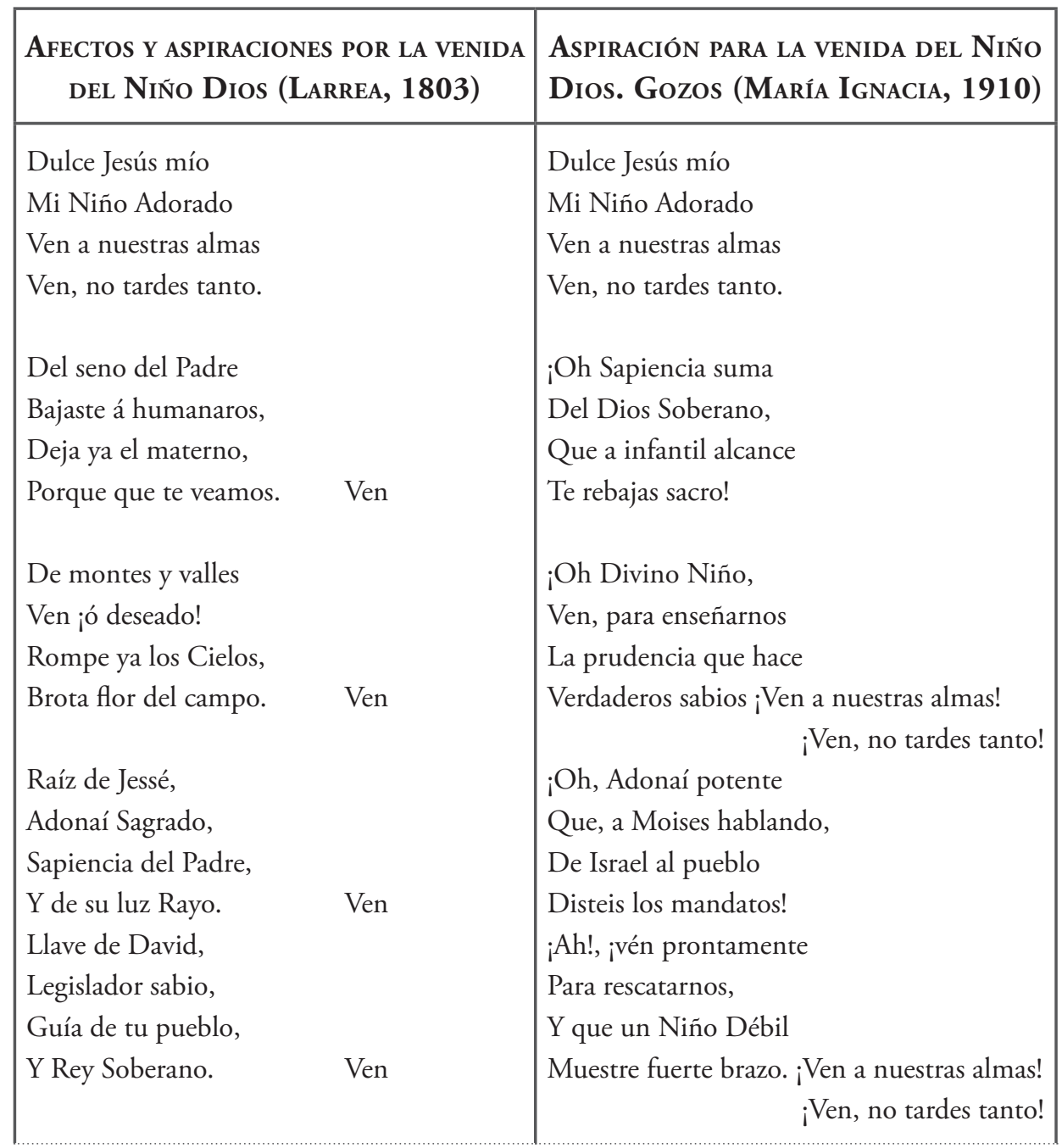




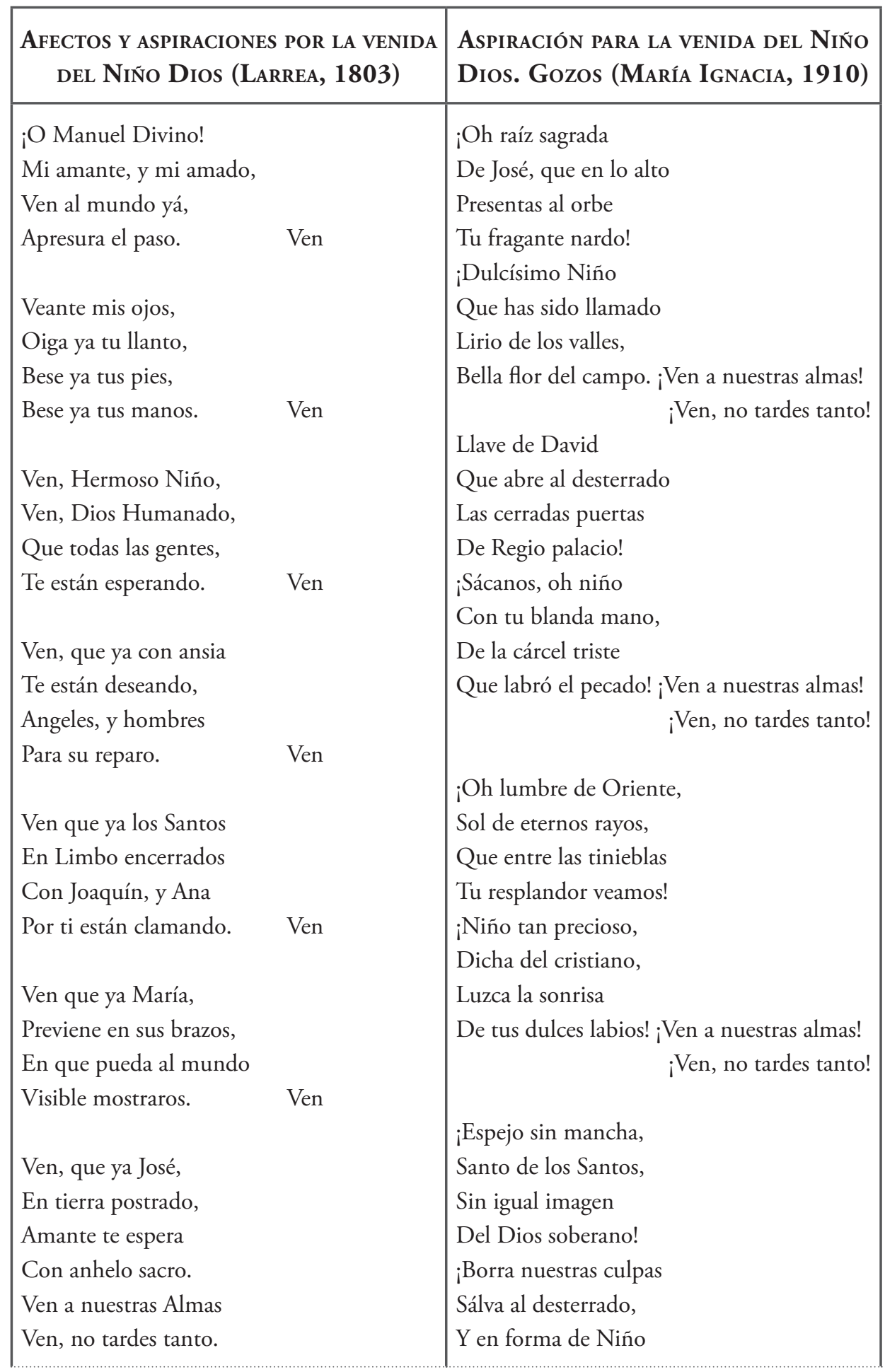




\begin{tabular}{|c|c|}
\hline $\begin{array}{c}\text { AFECTOS Y ASPIRACIONES POR LA VENIDA } \\
\text { DEL NiŃO DiOS (LARREA, 1803) }\end{array}$ & $\begin{array}{l}\text { AsPiración PARA la VENIdA del NiÑo } \\
\text { Dios. Gozos (María IgNaCIa, 1910) }\end{array}$ \\
\hline $\begin{array}{l}\text { Ven, Salvador nuestro } \\
\text { Por quien suspiramos. } \\
\text { Ven a nuestras almas, } \\
\text { Ven, no tardes tanto. }\end{array}$ & 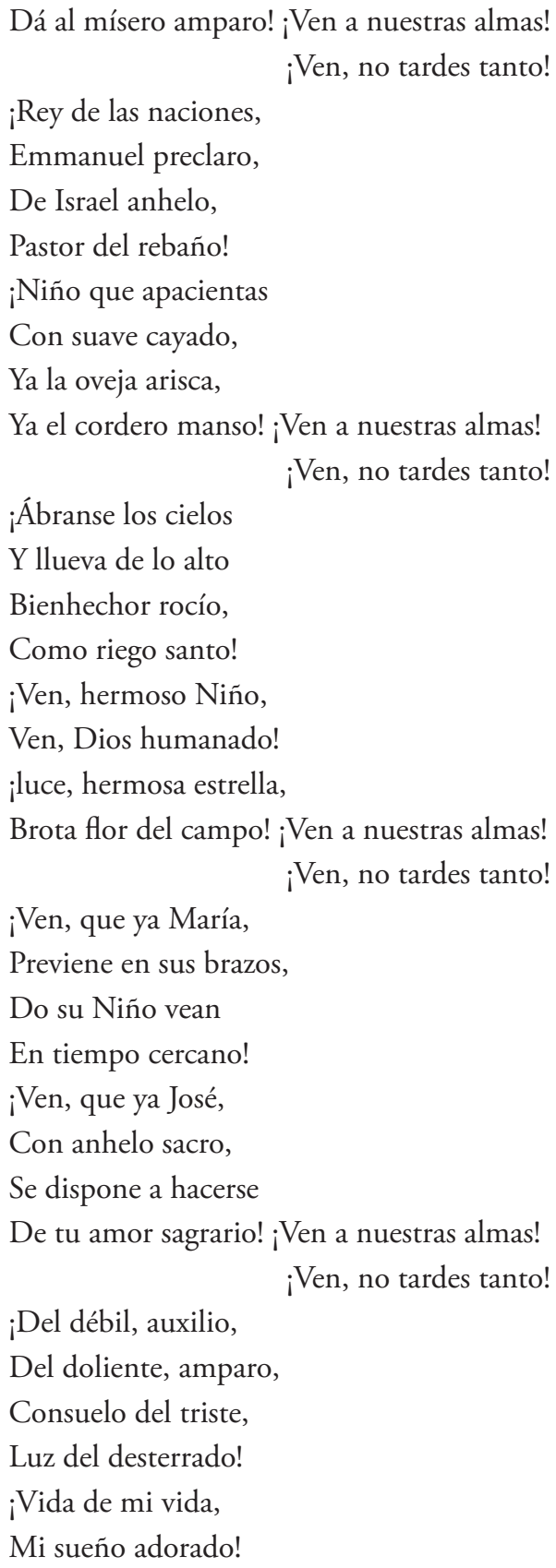 \\
\hline
\end{tabular}




\begin{tabular}{|c|c|}
\hline $\begin{array}{c}\text { AFECTOS Y ASPIRACIONES POR LA VENIDA } \\
\text { DEL NiŃo DiOS (LARREA, 1803) }\end{array}$ & $\begin{array}{l}\text { Aspiración PARA la VENIdA del Niño } \\
\text { Dios. Gozos (MARÍa IGNACIA, 1910) }\end{array}$ \\
\hline & $\begin{array}{l}\text { ¡Mi constante amigo, } \\
\text { Mi divino hermano! ¡Ven a nuestras almas! } \\
\text { ¡Ven, no tardes tanto! } \\
\text { ¡Véante mis ojos } \\
\text { De ti enamorados! } \\
\text { ¡Bese ya tus plantas! } \\
\text { ¡Bese ya tus manos! } \\
\text { ¡Prosternado en tierra } \\
\text { Te tiendo los brazos, } \\
\text { Y aún más que mis frases } \\
\text { Te dice mi llanto! ¡Ven a nuestras almas! } \\
\text { ¡Ven, no tardes tanto! } \\
\text { ¡Ven Salvador nuestro, Ven a nuestras } \\
\text { almas! } \\
\text { ¡Por quien suspiramos! ¡Ven, no tardes } \\
\text { tanto! }\end{array}$ \\
\hline
\end{tabular}

De cierto modo, es evidente que las aspiraciones propuestas por la madre María Ignacia no solo tienen un tanto de más sonoridad, sino que al estar escritas en verso pueden tener un grado de mayor recordación para los lectores, que además las repiten. Si se tiene en cuenta que las prácticas religiosas se reinventan periódicamente para así garantizar su pervivencia en las sociedades que cambian, la recreación hecha por la religiosa bogotana es novedosa porque permite un proceso de asimilación distinto, puesto que en esencia su obra da a las personas la posibilidad de recrear una práctica religiosa más acorde a su tiempo, ya sea con nuevas palabras o con términos más sencillos que brindan alegría y tal vez una sensación mucho más familiar por el estilo de la escritura, al dejar de lado la formalidad planteada en la versión original del sacerdote quiteño.

Desde su creación y a lo largo del siglo XIX, la Novena para el Aguinaldo no tuvo grandes modificaciones ante el público lector hasta la divulgación oficial de la versión recreada por la madre María Ignacia, obra que vio la luz en 1910 con la aprobación del arzobispo de Bogotá, Bernardo Herrera, quien por demás tomó los votos a la religiosa. Sin embargo ella no pudo, lamentablemente, 
ver circular su texto, dado que ese mismo año falleció "el día 31 de Julio a las $51 / 2$ de la tarde, a la edad de 51 ańos, y de vida religiosa 13 ańos, con 18 meses cumplidos", como consecuencia de un doloroso tumor en el pecho. Sobre sus últimos días de vida se relata que:

Al principio se rego cáncer, y aunque no fue de tan mala calidad no dejo de hacerla sufrir horriblemente, año y unos meses que lo tuvo reventado, pero con tanta paciencia que edificaba a todas y aun chanceándose del bulto que cargaba, pues era enorme lo que le creció, sentada en una silla se lo pasaba lo más del tiempo y escribiendo, apenas pudo estar en la cama el día en que murió, habiéndola administrado en la mańana de ese día, siguiendo muy decaída y como presintiendo su último momento que fue por la tarde, sin agonía ni [...] alguno entregó su alma a su Creador. La mañana siguiente se le cantó la vigilia y los Oficios fúnebres: fue la primera difunta que estuvo en el Coro bajo. Varios miembros de la familia la acompañaron a nuestro cementerio (Compañía de María Nuestra Señora, 1783-2003, f. 136).

Murió así la religiosa bogotana que inmortalizaría el fervor por la encarnación y el nacimiento del Hijo de Dios en el mundo a través de la reinvención de una obra con una larga historia. Las primeras décadas del siglo XX sirvieron como escenario para difundirla; la edición oficial se lanzó en noviembre de 1910, aprobada por el arzobispo con el nombre de Novena del Niño Dios, lo que implicó una modificación en el carácter religioso de la obra del padre Larrea, que tenía un lenguaje obsoleto, cargado de mortificación individual, y que fue reemplazado por la apertura pública de su rezo en un afán por extender la devoción al Niño Jesús y a la Sagrada Familia ${ }^{1}$.

De este modo, a través de las "Cartas Anuas" de la Orden de la Compañía de María Nuestra Señora en Colombia, correspondientes a 1927, se corrobora que la celebración de la Novena del Niño Dios de la madre María Ignacia se encontraba bien arraigada en el Colegio de La Enseńanza, puesto que hacia el final de las actividades escolares en el mes de octubre, y no en diciembre, se rezaba y se llevaban a cabo todos los festejos y actividades propias de la Navidad

1 Devoción recomendada por la venerable madre Margarita del Santísimo Sacramento, mujer de quien se influenció la madre María Ignacia en su paso por Europa. 
con el propósito de que todas las estudiantes (internas y externas) pudieran experimentarla en comunidad:

Como las fiestas de Navidad caen durante las vacaciones, se anticipan celebrándolas el 25 de Octubre, que es último que pasan reunidas. Se les arregla el Nacimiento como en Diciembre, hacen la Novena, con villancicos y con instrumentos pastoriles. El último día se reúnen en el salón de visitas: las colegialas internas dentro de las rejas, las niñas de la Escuela por fuera. Representan las primeras comedias alusivas al Nacimiento del Niño Jesús, terminadas las cuales se les reparte o distribuye el Arbol de Navidad que las antiguas alumnas (que asisten también al acto) han dispuesto en el mismo salón. Así termina el día, dejando a todas, llenas de contento.

Bogotá, Septiembre de 1927

(Compañía de María Nuestra Señora, Carta Anual de la Orden de las Hijas de Nuestra Señora. Relación de diversas Casas y Necrologías, 1926 al 1927, p. 56).

La madre Nora Tascón Cava, oDN, confirma la pervivencia de la celebración navideña acompañada de la Novena del Niño Dios en este mes en el Colegio hacia los ańos cuarenta y parte de los cincuenta del siglo $\mathrm{XX}$, momento en el cual ella era una de sus estudiantes: "Los 25 de octubre celebrábamos los 25 de diciembre, rezábamos la Novena del Niño Dios, había la Oración del Niño Jesús y las exalumnas [...] le celebraban a las nińas de la escuela gratuita el 25 también, con regalitos y celebraban la Novena”. La madre Tascón recuerda a su vez cuando fue rectora del colegio (entre 1972 y 1987): "Continuamos la mismas tradición [...] y en cada salón se hacía el pesebre. En un curso de segundo de bachillerato, trajeron [las estudiantes] un sobrinito [y] se vistieron ellas de San José y la Virgen" (comunicación personal con la madre Nora Tascón Cava, ODN, 15 de diciembre de 2016).

En los conventos y casas de la Compañía, adicionalmente a las actividades descritas para la celebración de la Navidad, todos los 25 de diciembre las hermanas hacen una procesión con la imagen del Niño Dios, que parte desde el refectorio y recorre los principales espacios de los claustros hasta llegar al altar consagrado al Niño, en donde ellas le "besan y cuentan algunos secretos". Esta ceremonia da paso al rezo del octavario, acompañado también por villancicos, pero alusivos y consagrados al nacimiento del Hijo de Dios (comunicación personal con la madre Nora Tascón Cava, ODN, 15 de diciembre de 2016). 


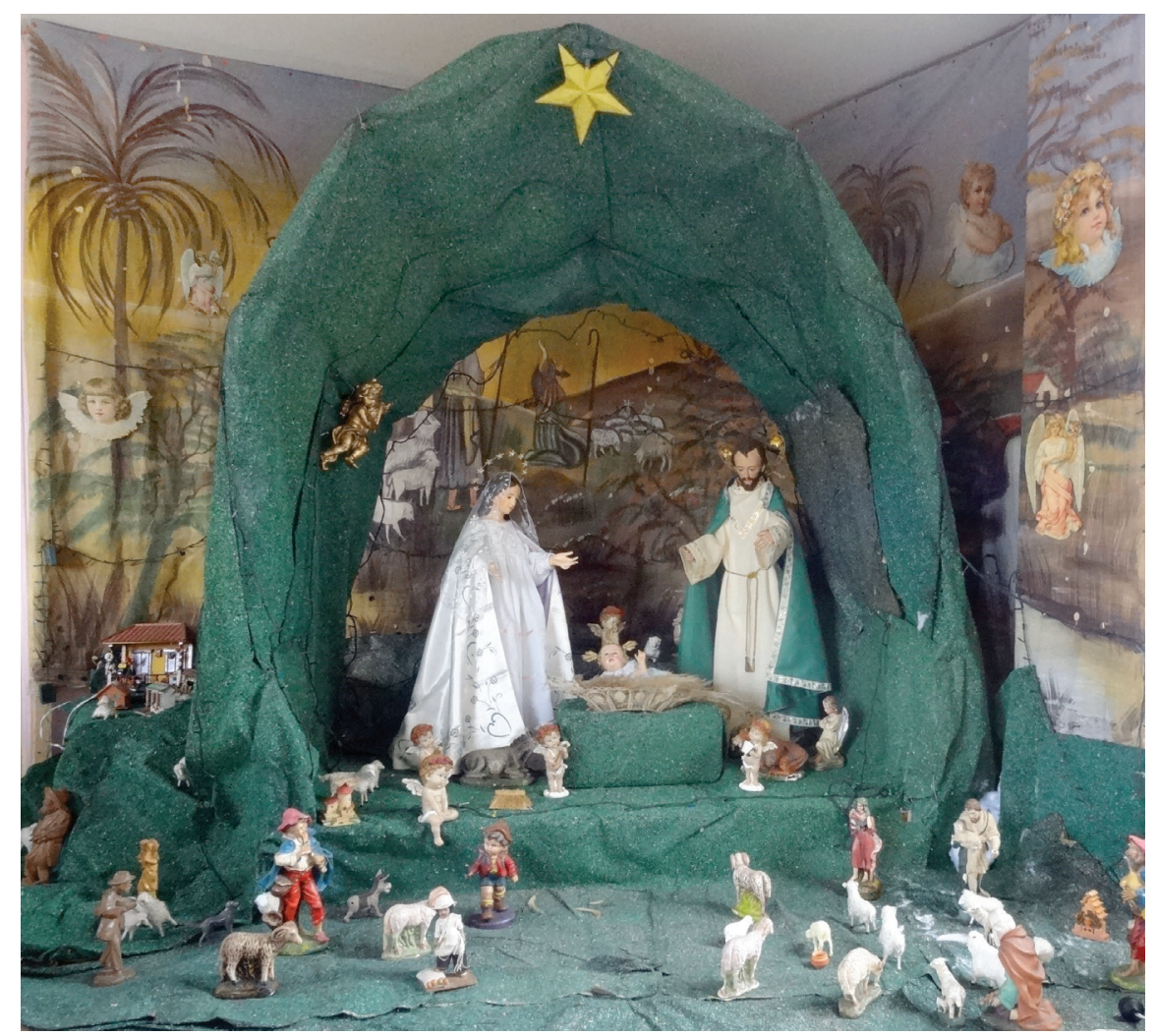

Figura 32. Pesebre compuesto por imágenes de mediano y gran tamaño. Casa de las Hermanas Mayores de la Compañía de María. Navidad de 2016 en Bogotá.

Fotografía de Fabián Leonardo Benavides Silva.

En síntesis, el legado de la madre María Ignacia fue traspasando los muros del Colegio de La Enseñanza gracias a la acción multiplicadora de las hermanas de la Compañía, quienes paciente y devotamente inculcaron en las mentes y almas de sus estudiantes la Novena del Niño Dios y la devoción por el Hijo de Dios en general, hasta tal punto "que todos los 25 de cada mes se tenía un acto especial de expresión de dicha devoción [con la Oración del Niño Jesús]" (comunicación personal con la madre María Helena Peña Afanador, oDN, 14 de noviembre de 2016). Así, la Compañía al tiempo que extendió su obra misionera con la erección de nuevas casas o conventos y, sobre todo, con la expansión de su proyecto educativo por el país a través de la apertura 
de diferentes sedes de La Enseñanza ${ }^{2}$, de los colegios nombrados en honor a santa Juana de Lestonnac ${ }^{3}$ o de la Institución Educativa Agroecológica La Playa (ubicada en el noroccidente de Nariño, municipio Francisco Pizarro) ${ }^{4}$, difundió durante el siglo XX entre muchos otros valores y principios, la devoción por la Novena del Niño Dios.

Sin duda, las generaciones de estudiantes de los colegios de la Compañía en mención (en la actualidad algunos de ellos mixtos), han desempeñado también un papel fundamental en la difusión y arraigo de la Novena entre sus familias y allegados, evidenciado en el hecho de que es una práctica sociorreligiosa vigente entre la población cristiana y particularmente católica, y por la misma impresión y circulación de numerosas ediciones de este texto en el trascurso de los siglos XX y XXI en Colombia, como se verá a continuación.

2 La Enseñanza, como ya se anotó, abrió sus puertas en Bogotá en 1783 y luego en Medellín (1889), Pereira (1926) y Barranquilla (1941).

3 Asimismo, los colegios fundados con el nombre de la santa Juana de Lestonnac para estudiantes con recursos económicos modestos o nulos se fueron estableciendo en Pereira (1962), Barranquilla (1964), Medellín (1966) y Bogotá (1969).

${ }^{4}$ Este plantel educativo se fundó en 1975 y cuenta con una población estudiantil principalmente afrocolombiana. 
